\title{
Construindo o fazer gerontológico pelas enfermeiras das Unidades de Estratégia Saúde da Família*
}

\author{
BUILDING THE GERONTOLOGICAL PERFORMANCE OF NURSES IN FAMILY HEALTH \\ PROGRAMS
}

\section{CONSTRUCCIÓN DEL QUEHACER GERONTOLÓGICO POR LAS ENFERMERAS DE LAS UNIDADES DE ESTRATEGIA SALUD DE LA FAMILIA}

\section{Sandra Helena Isse Polaroํㅜㄴ Lúcia Hisako Takase Gonçalves², Angela Maria Alvarez ${ }^{3}$}

\section{RESUMO}

Este artigo teve como objetivo descrever como as enfermeiras percebem a construção de seu fazer gerontológico no âmbito da Estratégia Saúde da Família em um distrito de Belém-PA. Os dados foram coletados entre ago/2009 a fev/2010, por meio de entrevista com catorze enfermeiras, e tratados pelo método de análise de conteúdo, gerando temas (entre eles a matéria do presente artigo - construindo o fazer gerontológico) e subtemas: consulta de enfermagem, visita domiciliar, atenção à família, parcerias para ações integradas e atuação em ações consolidadas. Do resultado infere-se que as vivências do fazer gerontológico das enfermeiras em seu cotidiano de trabalho são dificultadas principalmente pela insegurança no trabalho devido à violência urbana, pela deficitária estrutura funcional dos serviços e falta de capacitação específica em gerontogeriatria. Contudo, elas vêm construindo um fazer gerontológico peculiar, criando estratégias de ações integradas, possíveis em cada situação que se apresenta no processo do trabalho, com base em conhecimentos gerais de enfermagem que advêm de formação geral.

\section{DESCRITORES}

Idoso

Família

Enfermagem geriátrica

Programa Saúde da Família

\section{ABSTRACT}

The goal of this article is to analyze the development of gerontological nurses working in the Family Health Program in a municipal district in Belém, PA. Data have been collected through interviews with 14 nurses between 08/2009 and 02/2010 and have been analyzed using the content analysis method to generate topics. One such topic is the theme of this article: building gerontological work, and the sub-topics are the following: nursing consultation, home visits, family care, and seeking partnerships for integrated actions. According to the results, it may be inferred from nurses performing gerontological tasks that work is hampered primarily by urban violence, the inefficient functional structure of services and poor specific geriatric training. However, nurses have built a special "making of gerontology" by creating strategies of integrated actions according to each new situation that has been presented.

DESCRIPTORS
Aged
Family
Gerontological nursing
Family Health Program

\section{RESUMEN}

Se objetivó describir la percepción de las enfermeras sobre la construcción de su quehacer gerontológico en el ámbito de la Estrategia Salud de la Familia, en distrito de Belém-PA. Datos recolectados entre $08 / 2009$ y $02 / 2010$ mediante entrevista con 14 enfermeras, tratados según análisis de contenido, generando temas como la materia del presente artículo: construyendo el quehacer gerontológico y los subtemas: consulta de enfermería, visita domiciliaria, atención familiar, alianzas para acciones integradas y actuación en acciones consolidadas. Del resultado, se infiere que las experiencias del quehacer gerontológico de las enfermeras en su cotidiano son dificultadas por la inseguridad laboral debida a la violencia urbana, por la deficitaria estructura funcional de servicios y falta de capacitación específica en gerontogeriatría. No obstante, ellas vienen construyendo un quehacer gerontológico peculiar, creando estrategias de acciones integradas, posibles ante situaciones enfrentadas en el proceso laboral, basadas en conocimientos generales de enfermería adquiridos durante su formación general.

\author{
DESCRIPTORES \\ Anciano \\ Familia \\ Enfermería geriátrica \\ Programa de Salud Familiar
}

\footnotetext{
* Extraído da tese "Gerenciando o cuidado de enfermagem ao usuário idoso na Estratégia Saúde da Família", Programa de Pós-Graduação em Enfermagem da Universidade Federal de Santa Catarina, 2011. ${ }^{1}$ Enfermeira. Doutora em Enfermagem. Doutorado Interinstitucional pelo DINTER/UFPA/UFSC/CAPES. Professora Adjunta I da Faculdade de Enfermagem da Universidade Federal do Pará. Membro do Grupo de Estudos Educação, Formação e Gestão para a Práxis do Cuidado em Saúde e Enfermagem no Contexto Amazônico Belem, PA, Brasil. shpolaro@ufpa.br ${ }^{2}$ Enfermeira. Doutora em Enfermagem pela Escola de Enfermagem da Universidade de São Paulo. Professora do Programa de Pós-Graduação em Enfermagem da Universidade Federal de Santa Catarina. Pesquisadora Bolsa Produtividade em Pesquisa do CNPq. Membro do Grupo de Estudos sobre Cuidados de Saúde de Pessoas Idosas. Florianópolis, SC, Brasil. lucia.takase@pq.cnpq.br ${ }^{3}$ Enfermeira. Doutora em Filosofia da Enfermagem pelo Programa de Pós-Graduação em Enfermagem da Universidade Federal de Santa Catarina. Professora Adjunta do Departamento de Enfermagem da Universidade Federal de Santa Catarina. Coordenadora do Núcleo de Estudos da Terceira Idade. Membro do Grupo de Estudos sobre Cuidados de Saúde de Pessoas Idosas. Florianópolis, SC, Brasil. alvarez@ccs.ufsc.br
}

Rev Esc Enferm USP




\section{INTRODUÇÃo}

A visibilidade da enfermagem como profissão da saúde é evidenciada no senso comum pelo desenvolvimento de ações de cuidado a pessoas em processo de deterioração da saúde. Essa visão de cuidar é focada muitas vezes sobre as ações curativas das enfermeiras que atuavam, e ainda atuam, sob o enfoque biologicista apenas.

Entretanto, é na atenção primária, principalmente na $E S F$, que a enfermeira atuando na comunidade, junto à família, detecta fatores que podem causar danos à saúde do idoso e utiliza ações interativas e proativas, individuais e coletivas, que favorecem o viver e o envelhecer saudáveis. Esse é um cenário propício para a enfermagem gerontogeriátrica desenvolver-se como especialidade emergente, construindo e consolidando coletivamente suas ações junto ao usuário idoso e sua família.

Impõe-se aqui definir suas ações cuidativas específicas, fundamentadas nas mudanças que ocorrem ao longo do ciclo vital, de modo a contribuir na promoção do envelhecimento ativo e saudável e de melhor qualidade de vida possível das pessoas, considerando seus diferentes contextos socioculturais e circunstanciais de vida e saúde ${ }^{(1)}$.

O cuidar é um processo dinâmico, planejado com base no contexto do usuário. No âmbito da enfermagem gerontogeriátrica, o atendimento deve se realizar de forma integrada com outros saberes, com vistas a prever a integração das multidimensões do viver da pessoa idosa ${ }^{(2)}$, perspectiva que remete à interdisciplinaridade. É evidente que a interdisciplinaridade não traz respostas prontas, nem é solução para todos os problemas da prática profissional na atenção a saúde, mas se pode afirmar que as conexões e as correspondências estabelecidas entre as diversas disciplinas e seus respectivos profissionais tornam-na uma alternativa e contribuição importante.

0 processo de trabalho da enfermagem gerontogeriátrica na atenção primária deve estar direcionado para as especificidades da pessoa idosa, estabelecendo relações e criando vínculos com o idoso, a família e a comunidade, guardando sempre uma conduta ética. A atitude interativa, proativa, dialógica e compartilhada é a formula para buscar recursos para a solução dos problemas de saúde, a melhoria do bem-estar e a qualidade de vida dos usuários.

É esperado que os fundamentos da prática da enfermagem gerontológica sejam pautados em suas metas principais, a saber: promoção de um viver saudável; compensação de limitações e incapacidades; provisão de apoio e controle no curso do envelhecimento; tratamento e cuidados específicos e facilitação do processo de cuidar.
Alcançar tais metas pressupõe cumprir a função de atendimento integral do usuário idoso e sua família ${ }^{(2)}$.

A promoção do envelhecimento saudável enfatiza as medidas educativas com ações que orientam o idoso e demais indivíduos a preservar a saúde e melhorar suas habilidades funcionais, por meio da adoção de hábitos saudáveis de vida e abolição de comportamentos nocivos à saúde. Inclui também educação acerca dos cuidados e dos riscos ambientais que provocam acidentes (quedas), comprometendo sua capacidade funcional. Acompanhamento do estado de saúde-doença e cuidados continuados no processo de envelhecimento e de fragilização são essenciais na manutenção do idoso, com a melhor qualidade de vida possível, no seio da família e comunidade ${ }^{(2)}$.

O advento do Programa de Saúde da Família (PSF) em nosso país a partir de 1994, atualmente Estratégia Saúde da Família (ESF), como porta de entrada do SUS - Sistema Único de Saúde, representa um momento promissor para a especialidade da enfermagem gerontogeriátrica produzir os benefícios de suas ações especificas de cuidado junto dos usuários idosos e suas respectivas famílias, potenciais cuidadoras da vida futura dos idosos que envelhecem, fragilizam-se, podem adoecer e morrer ${ }^{(3-4)}$. Contudo, sabe-se que atualmente as enfermeiras contratadas nas equipes de PSF/ESF na maioria das vezes não são especializadas ou capacitadas para o cuidado dos idosos, usuários quase sempre encontrados nas famílias que atendem.

Reconhece-se todo o esforço na consolidação do SUS, que tem na atenção básica de saúde a porta de entrada para efetivá-lo, contudo continua sendo um grande impasse e desafio para os gestores garantir a integralidade e a qualidade de atenção aos usuários em todas as etapas do ciclo vital. É num cenário de incompletude, seja de recursos humanos capacitados, seja de recursos estruturais, entre outros, que a equipe do PSF/ESF, sobretudo as enfermeiras e a equipe de enfermagem, trabalham.

Estudos sobre condições de trabalho e qualidade das ações desenvolvidas pelas equipes do PSF/ESF demonstram, de modo geral, fragilidade no atendimento ao idoso, seja por desconhecimento do cuidado especifico na velhice, seja pela desarticulação no processo de trabalho ${ }^{(5-7)}$.

A inquietação de conhecer tais dificuldades em contextos específicos e encontrar encaminhamentos para o avanço do fazer enfermagem definiu a questão de pesquisa: Como as enfermeiras que atuam no PSF/ESF percebem seu atendimento prestado ao usuário idoso e sua família? E em que condições de trabalho? Tal questão emergiu de um estudo de tese de doutorado realizado junto às enfermeiras atuantes na ESF de um distrito de periferia do município de Belém ${ }^{(8)}$. 
O propósito deste artigo é apresentar respostas à questão da pesquisa, tendo o objetivo de descrever e analisar como as enfermeiras percebem a construção do seu fazer gerontológico no âmbito da ESF.

\section{MÉTODO}

O estudo foi desenvolvido em seis unidades de Saúde da Família do distrito D’Água, no município de Belém, área urbana onde prevalece maior concentração de habitantes de baixa renda. A escolha desse contexto se deve a esse município ser a capital da região Norte com maior população e cuja taxa de idosos atinge 7,6\% da população geral, cifra acima da média do Estado (7,0\%); sua população com alto índice de pobreza e com múltiplos problemas de saúde, conta com cobertura de apenas $22 \%$ de unidades de PSF/ESF ${ }^{(9)}$.

O estudo, de natureza exploratório-descritiva e de abordagem qualitativa, adotou a técnica de entrevista aberta guiada por um conjunto de perguntas disparadoras, como: Conte em detalhe um dia comum de seu trabaIho no PSF/ESF quando atende usuário idoso. Ao atender no programa HIPERDIA, o que você acrescenta de ações quando o usuário é idoso? Quando da visitação domiciliária à família com idoso, que ações desenvolve? Fale sobre as facilidades e as dificuldades que você encontra na rotina de seu trabalho ao atender o idoso e sua família.

A amostra foi composta por 14 enfermeiras, todas atuantes nas seis unidades de Saúde da Família do distrito em questão, por ocasião da coleta de dados. A mais jovem tinha 27 anos e a mais idosa, 64; a maioria tinha feito curso de especialização: oito em Saúde Pública ou Saúde da Família e quatro na área hospitalar. Doze começaram a trabalhar em saúde da família na primeira década de 2000 e duas, na década de 90. Dez colaram grau na década de 90 e quatro na primeira década de 2000.

As entrevistas ocorreram entre 08/2009 e 02/2010, após cada participante aceitar e assinar o Termo de Consentimento Livre e Esclarecido (TCLE), o qual teve uma cópia arquivada pela pesquisadora principal e outra entregue à própria participante a fim de manter a posse do documento com informações sobre sua participação no projeto, como também a garantia de sigilo de sua identidade no estudo.

O projeto seguiu as recomendações da Resolução 196/96 do Conselho Nacional de Saúde que dispõe sobre as normas éticas de pesquisa com seres humanos. Submetido ao Comitê de Ética em Pesquisa com seres humanos da Universidade Federal de Santa Catarina, foi aprovado por parecer exarado no processo protocolado sob n으 036/09.

O método de análise de conteúdo foi usado para o tratamento dos dados, valendo-se ainda da técnica de análise temática ou categorial ${ }^{(10)}$. O preparo da análise dos dados deu-se em três momentos: pré-análise; exploração do material; e tratamento dos resultados, inferência e interpretação.

Todo o material transcrito da entrevista foi composto em forma de um quadro que permitia, como segunda fase, a leitura flutuante, tendo como referência a questão de pesquisa para identificação das falas significantes. Elaborada a constituição do corpus, aplicaram-se as quatro regras que validam a pesquisa qualitativa: exaustividade - durante a leitura para identificar os significados; representatividade - verificando se as falas significantes extraídas representavam o todo; homogeneidade - na medida em que a escolha dos documentos obedeceu à conformidade, e pertinência - quando as falas significantes extraídas correspondiam à questão e ao objetivo da pesquisa.

No segundo momento de exploração do material, compôs-se os núcleos de significado correspondentes às falas significantes semelhantes, os quais configuraram um quadro de temas articulados: construindo o fazer gerontológico, gerenciando problemas, desafiando a violência e, como tema central, gerenciando o cuidado de enfermagem ao idoso no PSF/ESF ${ }^{(8)}$. No tratamento dos dados que resultaram em núcleos, o agrupamento por similaridades de significado no interior de cada núcleo constituiu os respectivos subtemas que os compõem.

O presente artigo representa um recorte desse estudo maior, apresentando o tema construindo o fazer gerontológico das enfermeiras do PSF/ESF atuantes num distrito de periferia da cidade de Belém, PA.

\section{RESULTADOS}

Foi na década de 90, com implantação do Sistema Único de Saúde e principalmente do PSF, transformada posteriormente em ESF, como porta de entrada do SUS, que as enfermeiras realmente ocuparam seu espaço na assistência básica e tiveram o mercado de trabalho ampliado. A partir daí, passaram a desenvolver mais efetivamente o cuidado de enfermagem aos usuários, incluindo os idosos e seus familiares, e assim foram construindo o seu fazer profissional.

As falas das enfermeiras neste estudo conduziram-nos a nominar a grande categoria temática emergida como construindo o fazer gerontológico e seus subtemas: fazendo consulta de enfermagem, fazendo visita domiciliar, dando atenção à família, buscando parcerias para ações integradas e atuando nas ações consolidadas. Assim, o fazer gerontológico consubstancia-se em cuidados do usuário idoso exercidos pelas enfermeiras adotando métodos e técnicas já conhecidos e costumeiramente usados na enfermagem geral.

- Fazendo a consulta de enfermagem - O processo de cuidar que permeia a aplicação da consulta de enfermagem aflora como forte instrumental da enfermeira no atendimento dos usuários e tem representado a principal estraté-
Construindo o fazer gerontológico pelas enfermeiras das Unidades de Estratégia Saúde da Família Polaro SHI, Gonçalves LHT, Alvarez AM 
gia na prática de suas funções. É realizando a consulta que interagem com os usuários e sistematizam sua ação cuidativa, estimulando-os a manter sua autonomia e independência, controlando a saúde e prevenindo agravos.

Na consulta, faço exame físico, ouço suas queixas. (...) quando começo o exame físico, com a proximidade, eles passam a falar mais, chegando até a contar problemas familiares (E2).

Com os usuários idosos temos mais cuidado, mais cautela, procuramos escutar mais do que falar. Tem idoso que chora, conta seus problemas (...) (E7, E14).

Na consulta, oriento sobre caminhada, alimentação, a importância do uso de medicamentos, (...) (E1, E4, E5).

(...) se tem dificuldade visual, auditiva, e andando sozinho, oriento para andar acompanhado, pensando em prevenir acidentes (E5).

Os depoimentos das enfermeiras revelam que a consulta de enfermagem focaliza principalmente os fatores de risco do idoso, estimulando-o a mudar para um estilo de vida mais seguro. É também nesse momento que algumas enfermeiras percebem a necessidade do idoso de se comunicar-se, dialogar. Assim, sua conduta é de escuta: ouvem mais do que falam, com toque humano e acolhedor, permitindo que surjam sentimentos mais calados ou secretos, procedendo de forma adequada para o idoso sentir-se acolhido nas unidades de saúde. Contudo, esse fazer gerontológico é uma construção própria das enfermeiras, muito mais movidas pela intuição e pela concepção humanística geral do fazer enfermagem, suprindo parte da falta de capacitação no atendimento às especificidades do cuidado do ser idoso.

As orientações especializadas da enfermagem gerontogeriátrica não foram ainda absorvidas pelas enfermeiras da ESF, que têm atendido o usuário idoso como a qualquer usuário, sem considerar as particularidades da idade. Mas, devido à sua formação voltada para a compreensão da integralidade do indivíduo, seus depoimentos mostram que a dimensão social por vezes é considerada no seu fazer cotidiano.

A gente pouco trabalha com ações grupais educativas, só orientação. O idoso vem pra gente com problema de saúde. Orientamos para ele participar em grupo de atividade física, atividades sociais (E5, E11).

Oriento a participar de algum grupo de igreja, porque lá vai se distrair mais, participar de atividade no bairro. Passamos a ter relação afetiva, pois alguns criam vínculo com a gente (E5).

Oriento que faça leitura, se gosta de ler, que assista televisão, ouça música, se reúna com amigos, não se isole de outras pessoas (E3).

Se é sedentário, oriento sobre a importância das caminhadas (E1, E6).
Observou-se que algumas enfermeiras já avançam, abordando questões sociais do mundo cotidiano. Durante a consulta trabalham a prática político-social, estimulando, mesmo que timidamente, a defesa dos direitos do cidadão:

Procuramos fazer com que o idoso tenha um atendimento digno, dentro de nossas limitações (E13).

Nossos idosos e famílias são conformados, passivos, digo que não podem ser assim, ponho na cabeça deles: vá e lute pelos direitos da falta de medicamentos, da demora de consultas com especialistas, da falta de transporte para levar o idoso para reabilitação, (...) mas não posso fazer muito isso porque se falarem que eu disse isso (...) já viu o que vai acontecer comigo (E2).

Destaque-se nesta prática que as enfermeiras têm, por vezes, desafios arriscados ao incentivar o usuário idoso a exercer seus direitos de cidadania e lutar para minimizar sofrimentos de grupos populacionais que vivem em condições de desigualdade social.

- Fazendo visita domiciliar - A visita domiciliar indubitavelmente proporciona à enfermeira um bom momento para desenvolver a observação. É quando ela detecta situações do cotidiano como condições de habitação, dinâmica familiar e estilo de vida que lhe mostra a rotina da família com mais clareza, permitindo a detecção precoce de necessidades de intervenção.

É durante a visita que observamos se a casa tem escada, se tem corrimão, orientamos pra que fique na parte de baixo. Se tem tapete, pedimos que retire porque ele pode escorregar e cair (...); se é a idosa quem cozinha, orientamos o uso da faca com cuidado para não se machucar (E3).

Observamos como o idoso é tratado na família, se mora sozinho ou com alguém. Como a família cuida do idoso, preocupa-se com o seu dia a dia, com sua higiene, sua alimentação (...) (E6).

(...) aqueles que têm dificuldade de vir, vamos à casa, lá fazemos o atendimento, orientamos no que for preciso, quando é um caso grave ficamos tratando na casa até conseguir o leito $(E 5, E 3)$. Vou à casa dos idosos que não se locomovem, (...) levamos nosso material, aparelho de pressão, fita de glicosímetro (...) (E8, E9).

(...) visitas a gente faz pra quem é acamado (...) a gente vai à casa do deficiente, fico ou mental (E10).

A visitação domiciliar, um dos pilares do trabalho na ESF, favorece especialmente usuários idosos no aprendizado da prática de manutenção ou recuperação da saúde, prevenção de agravos, bem como no cuidado daqueles mais fragilizados ou doentes. Assim admitem as enfermeiras, mas encontram vários entraves.

Visitas domiciliares são feitas, não com frequência, porque nossa unidade localiza-se em área vermelha - com muita violência urbana - o que dificulta nosso trabalho no domicílio. Além disso, temos muita demanda, seja espontânea ou programada na unidade (E4, E6). 
(...) tem idosos dentro da minha área que moram sozinhos, não têm filhos, sabemos que dentro da visita mensal são prioridade, mas nem sempre fazemos a visita, depende muito das outras demandas e da violência na área (E12).

- Dando atenção à família - No espaço familiar desse estudo, o cuidador principal e outros cuidadores estão presentes e são reconhecidos pelas enfermeiras:

A família (...) em geral, são as mulheres as cuidadoras. Elas sempre falam a respeito de marido, de filho, de preocupações que elas têm com a família (...) (E5).

(...) geralmente são as filhas que ficam em casa, estão sempre ocupadas, pouco conversam com o idoso. (...) Eles (os idosos) se sentem abandonados, sempre procuramos chamar a família para conversar, para melhorar o relacionamento (E11).

Outro aspecto observado é a baixa renda, que leva todos os membros a trabalharem para o sustento da família, deixando o idoso muitas vezes sozinho ou acompanhado por crianças ou outros familiares também necessitados. Percebe-se que o elo entre a enfermeira e a família permite detecção da real situação sociocultural e da dinâmica familiar e descobrir eventuais abusos e negligências.

\begin{abstract}
A facilidade é porque visitamos as famílias, temos acesso às casas, trabalhamos com as famílias cadastradas (...) Você tem como acompanhar todos esses idosos, tem o prontuário, tem toda a história desses pacientes, sabe-se quem são os familiares, toda a realidade deles, tanto social como cultural (E3, E7).
\end{abstract}

Eles vêm acompanhados; aqueles que não podem, vem uma pessoa da família com a receita (...) Tenho o prontuário, converso pra saber como ele está, transcrevo a medicação, oriento a família, faço a visita na casa do idoso (E8)

Procuro orientar a família quanto à higiene, alimentação, mas muitas vezes eles não têm recursos, pois moram em cima da água, não têm saneamento, não têm qualidade de vida (E9).

A facilidade é a interação com a comunidade, de conversar com as famílias, conseguindo colaboradores para o nosso trabalho (E13).

Contudo, existem muitas dificuldades para compatibilizar os preceitos da ESF com a realidade encontrada. As enfermeiras referiam facilidade em trabalhar com famílias pela boa aceitação, mas limitadas pelas precárias condições de vida e de saneamento básico, além do ambiente violento que ameaça continuamente a segurança de todos na comunidade, sendo o grande entrave para o bom desempenho da atenção aos usuários.

Um dos maiores entraves é a violência na área. Só podemos fazer visitas no horário cedo, até as 10 e com mais de um ACS, de preferência homem. Se a rua estiver agi- tada não se faz visita. A dificuldade maior é a segurança, para irmos com mais frequência nas casas (E1, E2, E3, E4, E5, E10, E11)

O medo do ambiente violento, um risco constante no cotidiano do trabalho da enfermeira, e não havendo qualquer providencia por parte dos gestores superiores, faziam-na juntamente com sua equipe aliarem-se com precário recurso local e conseguir algum apoio e proteção para se movimentar na comunidade.

Nós, a equipe, é que fazemos reunião com a comunidade. Nessa reunião, chamamos coordenadores de área, o centro comunitário, a polícia. Aí o que ficou decidido entre a gente, para poder trabalhar sem sofrer agressão, foi: a polícia chega de manhã, deixa o número do telefone do policial que está circulando no carro. A qualquer suspeita o acionamos (E10, E6, E7).

(...) Mas isso não foi feito pela SESMA (Secretaria de Saúde do Município); ela nada fez para nos proteger, fomos nós que buscamos alguma proteção (E10, E6, E7).

Os riscos e os enfrentamentos vivenciados pela equipe de saúde impressionam e preocupam, pois ameaçam a segurança no trabalho e comprometem o desempenho técnico de suas atividades. As enfermeiras tentam fazer articulação intersetorial dentro de sua governabilidade possível, mas nunca do modo esperado pelas Políticas de Atenção à Saúde de Pessoas Idosas.

- Buscando parcerias para ações integradas - O trabaIho na ESF dá autonomia para as enfermeiras atuarem na comunidade e é com esse trabalho que elas conquistam confiança e respeito da população, desenvolvendo-se ali uma relação de cumplicidade.

Durante a campanha de vacinação, buscamos ajuda da comunidade. Montamos os nossos postos na área de cobertura das equipes, em escolas, centros comunitários para que todos os idosos sejam beneficiados (E6, E7).

Às vezes a gente procura o centro comunitário para fazer uma mobilização com os idosos, verificar a pressão, fazer palestra nas associações do bairro, solicitando ajuda (E11, E12).

A partir do momento que o idoso chega na unidade e passa mal, atendemos enquanto aguardamos a 192: faz-se todos os procedimentos dentro da possibilidade da nossa unidade (E6).

Se houver necessidade de consulta médica com certa urgência, chamo a médica, ela vem e atende na mesma hora, aqui junto comigo (...); se o idoso tem algum problema, o ACS vai à casa ver como ele está, se está melhorando (E9).

Embora os agentes de saúde não sejam obrigados a trabalhar assim diretamente na campanha da vacinação (...), pedimos a eles que façam a mobilização de toda a comunidade (E9, E11).
Construindo o fazer gerontológico pelas enfermeiras das Unidades de Estratégia Saúde da Família Polaro SHI, Gonçalves LHT, Alvarez AM 
- Atuando em ações consolidadas - O HIPERDIA - Sistema de Cadastramento e Acompanhamento de Hipertensos e Diabéticos - e o Programa Nacional de Imunização para Idoso são os únicos programas assumidos pelo município do presente estudo nos quais o idoso está inserido e onde as enfermeiras têm atuação marcante.

O HIPERDIA é desenvolvido em seu formato original indiscriminadamente pra todos os usuários hipertensos e diabéticos sem qualquer orientação específica quando do usuário idoso. Mesmo assim, as enfermeiras demonstravam sensibilidade frente ao usuário idoso, atendendo intuitivamente, desenvolvendo ações diferenciadas mais próximas das desejáveis para o idoso.

Converso para saber se o idoso toma medicação, se tem alguma queixa ou outros problemas, se há necessidade de especialistas (E5).

Se é obeso procuro saber sobre seus hábitos de alimentação, quem o ajuda no preparo da refeição, tento ajudar (...) faz-se encaminhamento para o serviço de referência. No retorno ele passa por nós na unidade da ESF e dá continuidade de atendimento (E6).

Caso observe outras necessidades, é feito através da ficha de referência e contrarreferência (...) para a central de marcação (E3, E9).

Neste estudo, as enfermeiras capacitavam sua equipe e juntamente com os Agentes Comunitários de Saúde, técnicos e auxiliares de enfermagem, envolviam-se em ações, desde planejamento, divulgação, controle das vacinas e até o resgate dos idosos faltosos por meio de busca ativa.

Estou na coordenação da campanha, (...) aplicamos vacina na unidade e nas casas para os que não podem se locomover (E1, E3, E5, E7, E8, E10, E11, E12, E14).

Trabalhamos muito essa questão da vacinação (...), a gente procura resgatar os idosos que não se vacinaram (E2, E3, E4, E5, E11).

Quando não se atinge a meta, se faz a intensificação (...) levando vacinas (E6).

Na campanha da vacinação as enfermeiras encontram rara condição adequada de trabalho, quando todos os recursos são colocados à disposição para o desenvolvimento das ações especificas. É a enfermagem, por excelência o componente da equipe que mais se empenha para o sucesso da campanha.

\section{DISCUSSÃO}

A prática da enfermagem junto à pessoa idosa na atenção primária deveria estar focada nas necessidades especiais de vida e saúde, buscando estabelecer vínculos com a família e comunidade em torno de sua residência. Atitudes interativa, proativa, dialógica e compartilhada seria a fórmula para buscar recursos, dissipar problemas e imprimir certa melhoria na saúde das pessoas. Nessa perspectiva, a assistência de enfermagem ao idoso haveria de se consolidar a partir de conhecimentos e habilidades especificas experimentadas na prática diária. Seria especificamente na ESF que as enfermeiras atuando na comunidade junto das famílias, teriam a oportunidade de captar multifatores que influenciam o equilíbrio da saúde dos idosos e desenvolver ações de promoção do envelhecer mais saudável ${ }^{(2-3)}$.

Tal ideário está ainda longe de ser praticado pelas enfermeiras deste estudo, atuantes no PSF/ESF, como foi observado em seu fazer gerontológico. Revela o hiato entre a academia e o campo prático, demonstrando insuficiência na formação e capacitação específica da enfermeira e de todo o corpo da enfermagem, como também na educação permanente no serviço.

Entre os diversos fazeres das enfermeiras do estudo, sobressai a prática da consulta de enfermagem, parte da metodologia da sistematização da assistência de enfermagem. Tal instrumental está integrado em seu fazer profissional, porque há tempo a consulta de enfermagem está legitimada pela Lei do Exercício Profissional e regulamentada como atividade privativa do enfermeiro ${ }^{(11)}$. A consulta de enfermagem tem favorecido intervir também na dimensão social, pois a enfermagem enquanto prática social, tem sua ação ampliada, fazendo conexões entre os determinantes sociais e o processo saúde/doença, considerando o usuário como sujeito partícipe de seu contexto social. Contudo, esse esforço é ainda um desafio na prática diária, a incorporação de concepções ainda novas do trabalho focado na família no contexto na ESF.

Em um estudo sobre concepções de cuidado encontradas nas teses de doutorado de um programa de pós-graduação de enfermagem defendidas entre 1995 e 2005, identificou-se a prevalência de ações de enfermagem no fazer técnico e eventualmente ações proativas de intervenção social|(12). Tal avaliação confirma nossos achados de as enfermeiras eventualmente atuarem na promoção da cidadania, sobretudo entre idosos, explorando ações concretas às questões sociais encontradas.

Embora a consulta de enfermagem tenha sido incorporada como instrumento pela enfermeira no PSF/ESF, falta-Ihe completude no trato das necessidades multidimensionais dos usuários e especificidade de ações interventivas no tocante aos idosos e suas famílias. Convivendo em determinado contexto comunitário, agem muito mais intuitivamente do que aplicando conhecimentos de enfermagem gerontogeriátrica, alegando que lhes falta capacitação.

Já a visitação domiciliar é praticada e percebida pelas enfermeiras como método e instrumento importante que lhes permite estabelecer relações de vínculo e acolhimento da família, dando atenção às famílias além 
dos idosos obviamente, contudo, sem a especificidade de cuidados gerontológicos que requer. Tal constatação confirma que desde que se conhece a enfermagem como profissão, sempre se ensinou e se praticou a visitação domiciliar ${ }^{(13)}$. As enfermeiras pareciam praticá-la com desenvoltura, atendendo aos ditames da PSF/ESF ${ }^{14-}$ 15), valendo-se de conhecimentos e habilidades gerais aprendidas nos bancos acadêmicos.

Outra dificuldade importante por elas relatadas na realização de visita domiciliar às famílias com idosos é o ambiente de violência urbana prevalente nas periferias pobres da cidade onde ocorreu o estudo, colocando em risco a segurança de todos e restringindo a liberdade do ir e vir na comunidade. Situação semelhante foi constatada num estudo feito em unidade básica de saúde de uma comunidade carente de Rio Grande do Sul ${ }^{(14)}$, fazendo seus autores enfatizarem a necessidade de ações políticas urgentes de esforço intersetorial na resolução da questão que impede ou constrange a ação cotidiano dos serviços de saúde na família e comunidade.

Em meio a tais dificuldades, entre outras, as enfermeiras fazem parceria para ações integradas possíveis, com os recursos precários da comunidade circundante, desenvolvendo relação de cumplicidade com os membros da equipe de trabalho. Semelhante situação encontra registro em diversos estudos realizados no país em âmbito de trabalho das unidades de PSF/ $\mathrm{ESF}^{(7-8,16)}$. Por exemplo, no estudo na ESF, em Belém, as enfermeiras diante das deficiências de atendimento, e vendo-se premidas pela necessidade de atender um usuário idoso em situação crítica e urgente, valem-se da cidadania de relação recorrendo a colegas de trabalho, até de outras unidades ou serviços, para ver o seu usuário atendido.

As enfermeiras sendo um dos profissionais essenciais na equipe ESF e quase sempre presentes nas unidades estabelecidas no país, quando em contextos de grandes dificuldades de todas as ordens, como o caso do presente estudo, e não podendo fazer as parcerias formais, valem-se do recurso de companheirismo entre colegas, para atender os usuários em situações mais críticas.

Já em programas assumidos pelo Município, as enfermeiras encontram rara condição de trabalho no atendimento dos usuários atuando em ações consolidadas como no programa HIPERDIA e Programa Nacional de Imunização do Idoso - Campanha contra a gripe, uma ação pontual realizada em período limitado determinado pelo MS, cujos recursos são amplamente disponibilizados.

O programa HIPERDIA, por ser um sistema contínuo, as condições de trabalho diferem entre as unidades, segundo os recursos alocados. As enfermeiras nesse estudo demonstraram atuar no programa com atenção aos seus participantes de modo geral,com pouca descriminação de cuidados específicos requeridos pelos idosos.
Quanto à campanha de vacinação, as enfermeiras atuam na equipe de trabalho liderando as ações contra a influenza em idosos e percebem-se como membro ativo por excelência no sucesso dessa vacinação. Observações da prática tem demonstrado isso como também achados de pesquisa como a realizada em um município de São Paulo comprovam que as enfermeiras trabalham tanto na administração, no planejamento e na execução da ação(17). Tal campanha, contudo, tem merecido empenho junto ao Ministério da Saúde(18) cuja agenda de realização obrigatória anual no mês de abril, não se adéqua à peculiaridade climática regional do Norte, especialmente do Pará, em que o período mais chuvoso, entre janeiro e março, torna os idosos mais vulneráveis à gripe.

\section{CONCLUSÃO}

Em síntese, as enfermeiras das Unidades da Estratégia Saúde da Família do distrito de Belém encontram dificuldades em seu processo de trabalho, como: a) condições deficitárias de infraestrutura funcional dos serviços; b) falta de capacitação específica e educação permanente em gerontogeriatria; c) insegurança para ir e vir ao trabalho pela prevalência de violência urbana no território adstrito.

Quanto à atuação junto aos usuários idosos e suas famílias, conseguem: a) mostrar-se mais competentes quando atuam em ações consolidadas, como o HIPERDIA e a Campanha Nacional de Vacinação do Idoso, demonstrando que quando recursos e condições estão disponíveis, seu trabalho é desenvolvido com empenho e com relativo sucesso, mesmo carecendo de capacitação específica; b) mesmo com todas as dificuldades cotidianas encontradas, têm construído um fazer gerontológico peculiar, aplicando o instrumental da consulta de enfermagem e da visitação domiciliária, valendo-se da experiência diária e dos conhecimentos básicos adquiridos nos bancos universitários. Com os conhecimentos de prática social, articulam parcerias entre a equipe de trabalho, os usuários, a comunidade e serviços presentes na área adstrita, criando estratégias a cada situação para ações integradas possíveis e contornando a fragmentação do atendimento prevalente.

Do resultado infere-se que a vivência do fazer gerontológico das enfermeiras em seu processo de trabalho em Unidades da Estratégia Saúde da Família chama pela alocação mais justa de recursos humanos capacitados por meio de educação permanente, como também provimento de infraestrutura mínima para o funcionamento adequado dos serviços. Impõem-se aqui esforços e vontade política dos gestores de saúde do município para reavaliar o status quo do sistema em funcionamento e admitir as pactuações necessárias no oferecimento de programas prioritários que a população local aguarda, entre os quais a atenção à saúde do idoso.
Construindo o fazer gerontológico pelas enfermeiras das Unidades de Estratégia Saúde da Família Polaro SHI, Gonçalves LHT, Alvarez AM 
1. Brasil. Ministério da Saúde; Secretaria de Atenção à Saúde, Departamento de Atenção Básica. Envelhecimento e saúde da pessoa idosa. Brasília; 2007. (Cadernos de Atenção Básica, n.19).

2. Gonçalves LHT. A complexidade do cuidado na prática cotidiana da enfermagem gerontogeriátrica. Rev Bras Geriatr Gerontol. 2010;13(3):507-18.

3. Gonçalves LHT, Alvarez AM, Santos SMA. O cuidado na enfermagem gerontogeriátrica: conceito e prática. In: Freitas EV, organizador. Tratado de geriatria e gerontologia. $3^{\mathbf{a}}$ ed. Rio de Janeiro: Guanabara-Koogan; 2011. p. 1263-69.

4. Araujo I, Paúl C, Martins M. Living older in the family context: dependency in self-care. Rev Esc Enferm USP [Internet]. 2011 [cited 2011 Nov 22];45(4):869-75. Available from: http://www.scielo.br/pdf/reeusp/v45n4/en_v45n4a11.pdf

5. Motta LB, Aguiar AC, Caldas CP. Estratégia Saúde da Família e a atenção ao idoso: experiências em três municípios brasileiros. Cad Saúde Pública. 2011;27(4):779-86.

6. Lima MADS, Ruckert TR, Santos JLG, Colome IES, Acosta AM. Atendimento aos usuários em situação de violência: concepções dos profissionais de unidades básicas de saúde. Rev Gaúcha Enferm. 2009;30(4):625-32.

7. Colome ICS, Lima MADS, Davis R. Visão de enfermeiras sobre as articulações das ações de saúde entre profissionais de equipes de saúde da família. Rev Esc Enferm USP. 2008;42(2):256-61.

8. Polaro SHI. Gerenciando o cuidado de enfermagem ao usuário idoso na Estratégia Saúde da Família [tese doutorado]. Florianópolis: Programa de Pós-Graduação em Enfermagem, Universidade Federal de Santa Catarina; 2011.

9. Pará. Secretaria de Saúde do Estado; Coordenação Estadual Saúde do Idoso. Nota técnica. Belém: SESPA; 2010.
10. Bardin L. Análise de conteúdo. Lisboa: Edições 70; 2009.

11. Brasil. Lei n. 7.498, de 25 de julho de 1986 . Dispõe sobre a regulamentação do exercício profissional da Enfermagem e dá providências [Internet]. Brasília; 1986 [citado 2010 jul. 12]. Disponível em: http://www.corensc.org.br/Empresa2/ lei7498.html

12. Backes DS, Erdmann AL, Büscher A. Evidenciando o cuidado de enfermagem como prática social. Rev Latino Am Enferm. 2009;17(6):988-94.

13. Lopes WO, Saupe R, Massaroli A. Visita domiciliar: tecnologia para o cuidado, o ensino e a pesquisa. Ciênc Cuid Saúde. 2008;7(2):241-7.

14. Takahashi RF, Oliveira MAC. A visita domiciliária no contexto da Saúde da Família. In: Brasil. Ministério da Saúde; Instituto para o Desenvolvimento da Saúde; Universidade de São Paulo. Manual de enfermagem. Brasília: Ministério da Saúde; 2001. p. 43-6.

15. Figueiredo MHJS, Martins MMFPS. From practice contexts towards the (co) construction of family nursing care models. Rev Esc Enferm USP [Internet]. 2009 [cited 2011 Nov 12];43(3):615-21. Available from: http://www.scielo.br/pdf/ reeusp/v43n3/en_a17v43n3.pdf

16. Araújo MBS, Rocha PM. Trabalho em equipe: um desafio para a consolidação da estratégia de saúde da família. Ciênc Saúde Coletiva. 2007;12(2):455-64.

17. Reis PO, Nozawa MR. Análise do Programa de Vacinação de Idosos de Campinas, SP. Ciênc Saúde Coletiva. 2007;12(5):1353-61.

18. Brasil. Ministério da Saúde; Secretaria de Vigilância em Saúde. Influenza: Informe Técnico da 12a Campanha Nacional de Vacinação do Idoso [Internet]. Brasília; 2010 [citado 2011 nov. 23]. Disponível em: http://portal.saude.gov.br/portal/ arquivos/pdf/informe_tec_influenza_sazonal_2010.pdf 